\title{
Research Capacity for Prevention and Control of Non-communicable Diseases and Their Risk Factors in Nepal: Findings of a Needs Assessment Study
}

\author{
Natalia Oli ( $\square$ olinatalia1@gmail.com ) \\ Department of Community Medicine, Kathmandu Medical College Public Limited, Sinamangal, Kathmandu \\ Pranil MS Pradhan \\ Department of Community Medicine, Institute of Medicine, Maharajganj, Kathmandu \\ Reshu A Sagtani \\ Department of Community Health, Patan Academy of Health Sciences, Lalitpur \\ Archana Shrestha \\ Department of Public Health, Kathmandu University School of Medical Sciences, Dhulikhel \\ Lindsay M. Jaacks \\ Global Academy of Agriculture and Food Security, The University of Edinburgh, Midlothian \\ Biraj Karmacharya \\ Department of Community Medicine, Dhulikhel Hospital-Kathmandu University Hospital, Kavrepalanchwok \\ Goodarz Danaei \\ Department of Global Health and Population, Harvard T.H. Chan School of Public Health, Boston, MA \\ Abhinav Vaidya \\ Department of Community Medicine, Kathmandu Medical College Public Limited, Sinamangal, Kathmandu
}

\section{Research Article}

Keywords: Community Medicine, Curriculum, Public health, Need assessment, Non-communicable diseases, Research methodology, Risk factors

Posted Date: August 17th, 2021

DOI: https://doi.org/10.21203/rs.3.rs-788008/v1

License: @ (i) This work is licensed under a Creative Commons Attribution 4.0 International License. Read Full License 


\section{Abstract}

\section{Background}

Despite a high burden, there is limited training available in non-communicable disease research in Nepal. In order to understand research capacity gap in noncommunicable diseases in the country, we conducted a needs assessment. We aimed to assess existing research training capacity in academic health institutions of Nepal for the prevention and control of non-communicable diseases, identify gaps in research training in these institutions, and explore the feasibility of developing research training program in Nepal targeting non-communicable diseases and their risk factors.

\section{Methods}

We did qualitative and quantitative research and reviewed academic institution curricula review and scientific literature. We conducted 14 Focus Group Discussions with bachelor and Masters level students of public health and community medicine; 25 In-depth Interviews with department heads and faculties, and government stakeholders. We surveyed medical and public health students on their research knowledge and skills development. Further, we reviewed university curricula of bachelors in medicine and public health Masters in community medicine and public health. We also reviewed non-communicable disease related scientific articles authored by Nepali researchers.

\section{Results}

We found that the research methodology component was addressed differently across academic programs. One-third (33.7\%) of students expressed lack of skills for analysis and interpretation of data. They felt that there is a wide scope and career-interest in non-communicable diseases research in Nepal. However, specific objectives in the curriculum and practical aspects regarding non-communicable diseases were lacking. Most of the non-communicable diseases research in Nepal are prevalence studies. Most of the studies did not have any financial support. Lack of funding, conflicting priorities with curative services, and inadequate training for advanced research tools were reported as major barriers. Likewise, availability of trained human resources and international funding for non-communicable diseases research were perceived facilitators.

\section{Conclusions}

Nepal must strengthen the whole spectrum of research capacity: epidemiological skills, research management, and fund generation. University curricula should match up with the disease burden and must emphasize on applied practical research projects. Generation of a critical mass of non-communicable disease researchers must go together with improved funding from the government, non-governmental organizations, and external funding organizations.

\section{Background}

Currently, low and middle-income countries (LMICs) are facing a rapidly rising burden of non-communicable diseases (NCDs) [1] and one of the essential strategies to tackle the problem is development of local research capacity to explore and address NCDs and their risk factors [2]. Four out of five of global NCD-related deaths occur in LMICs and it is expected that this proportion will rise in the future [3]. In Nepal, $60 \%$ of disability-adjusted life-years is attributed to NCDs, and behavioral and environmental risk factors are major contributors [4, 5]. Behavioral risk factors such as tobacco, alcohol, unhealthy diet, physical inactivity, high blood pressure, and high body mass index are prevalent in the Nepalese population [6]. Furthermore, environmental risks such as ambient [7] and indoor [8] air pollution are prevalent, and important contributors to NCDs in the country, particularly chronic obstructive pulmonary diseases (COPD) with a nation-wide prevalence of $11.7 \%$ [9].

Nepal's Multi-sectoral Action Plan for the Prevention and Control of NCDs intends to address NCDs through various strategies including research and surveillance [10]. However, implementation of many of the research components of the Multi-sectoral Action Plan have been limited by a shortage of trained researchers [11]. One major reason for this lack of human resources is the fact that there are limited training opportunities in NCDs research in Nepal. Even though the country has numerous institutes that provide training in public health and other allied health sciences, these courses cover general public health and research methodology, and do not adequately encompass specific domains such as NCDs. Furthermore, the disciplines such as public health, environment, nutrition, sociology, and medicine work in silos- and hence a holistic approach to study a multi-sectoral issue such as NCDs is often lacking. Indeed, the complexity of tackling NCDs and their risk factors necessitates researchers with multidisciplinary research training and support [12].

A strong health research capacity is crucial to establish context-specific evidence-based clinical practice guidelines and public health policies [13, 14]. Many LMICs lack health research capacity, which limits their ability to identify and respond to local health needs. Also, it often is a major barrier for LMICs to equitably participate in the international response to global health challenges [14, 15]. Major gaps and deficiencies in research capacity in many LMICs include low priority for research, insufficient prioritization of problems addressed by research, limited trained research human resources, inadequate application of research findings in decision-making including government policy, lack of applied knowledge, lack of funding and issues with monitoring and evaluation of research impact [16].

In order to understand this research capacity gap and develop a comprehensive plan to fill it, a systematic needs assessment was conducted by Kathmandu Medical College Public Limited (KMCPL) in collaboration with three leading health institutions of Nepal, Kathmandu University School of Medical Sciences (KUSMS), Patan Academy of Health Sciences (PAHS) and Institute of Medicine, Tribhuvan University (IOM), and the Harvard TH Chan School of Public Health. This was part of a larger project, known as bRISK (Building research capacity for prevention and control of non-communicable disease risk factors in Nepalese population), which ultimately aims to develop a comprehensive research training program for the prevention and control of NCDs and their risk factors in Nepal. The objectives of the initial needs assessment, reported in this paper, were: (1) to assess existing research and research training capacity in academic health institutions of Nepal for the prevention and control of NCDs and their risk factors, (2) to identify gaps in research training, faculty development, 
scientific environment, and administrative resources in these institutions, (3) to explore the feasibility of developing a new or continued research training program in Nepal targeting NCDs and their risk factors.

\section{Methods}

The needs assessment was conducted between June and September 2020 in Nepal using a mixed method approach. We did qualitative and quantitative research, included academic institution curricula review and scientific literature review (Fig. 1). Findings of the qualitative, quantitative studies, and document review were triangulated to obtain comprehensive, in-depth results.

\section{Desk review of curricula and scientific literature}

We mapped academic health institutions across the country that conduct the following academic programs: MD Community Medicine, Masters in Public Health (MPH), Bachelor in Medicine and Bachelor in Surgery (MBBS) and Bachelor in Public Health (BPH). A total of six universities consisting of 14 affiliated academic institutes were listed. The majority (12 out of 14) of the academic institutions were located in three of Nepal's seven provinces (Province 1, Bagmati Province, and Gandaki province) (Fig. 2). Each university has its own curriculum for the academic programs mentioned above. We reviewed curricula of the universities for the following programs available in those universities: MBBS (six universities), BPH (three universities), MD community medicine (two universities), and MPH (six universities). We aimed to explore the integration of NCDs and their risk factors and research in the curricula and curricula implementation in different academic health institutions of Nepal.

Another component of our desk review was identifying recent scientific articles authored by Nepali researchers in the field of NCDs published between January 2010 and December 2019 and available in PUBMED. We used the following keywords: "risk factor", "cardiovascular disease", "cancer", "diabetes", "COPD", "Nepal". Altogether 120 articles were retrieved after title and abstract review. Articles published by authors affiliated with local institutions and organizations as well as those published by Nepali researchers who work or study outside the country but conduct their research in Nepal as a first author were included in the review. Data abstraction form was created and contained following sections: researchers' affiliation to academic or non-academic organization of Nepal, type of study, availability of the local or international funding, area of research, outcomes measured.

\section{Qualitative study}

We conducted 14 Focus Group Discussions (FGDs), 25 In-depth Interviews (IDIs), and six Key Informant Interviews (KIIs) across three provinces. We applied convenience sampling and enrolled altogether 107 students of $\mathrm{BPH}, \mathrm{MPH}$, and MD community medicine programs across 11 academic institutes for the FGDs (Fig. 2).

The FGDs were aimed at exploring students' perceptions regarding coverage of research methodology in their curriculum, particularly research in NCDs and their risk factors, their opinion on curricula implementation in their academic institutions, and barriers and facilitating factors for pursuing a research career in NCDs. Each FGD had 8-10 participants and lasted approximately 90 minutes.

We also conducted 25 IDIs and six KIls with various stakeholders, including the heads of departments of public health and community medicine, faculties involved in teaching NCDs modules, representatives from the Institutional Review Committee, and experts from environment and nutrition fields. We also interviewed government stakeholders from the Epidemiology and Disease Control Division (EDCD), National Health Training Center (NHTC), and Nepal Health Research Council (NHRC), an ethical and research governing body under Ministry of Health and Population. Respondents for IDIs were selected on the basis of their expertise and their availability at the time of the interview. Interviews queried the stakeholders' perceptions regarding the prioritization of NCD research; training and funding opportunities; how curricula address NCD research; motivating factors for involvement of faculty and students in NCD research; and the proportion of NCD-related proposals submitted to Institutional Review Committees. KIls and IDIs were carried out at the respondents' working place in a separate room and lasted approximately 60 minutes.

All FGDs and interviews were taped using tape recorder after obtaining consent. The recordings were transcribed and then translated from Nepali into English for coding and analysis. Data were analyzed using thematic analysis. We generated a codebook from the transcribed data. Codes were then analyzed for recurring themes.

\section{Quantitative survey}

We conducted a quantitative online survey among the final year students of MPH, MD community medicine and BPH, and fourth-year MBBS students as they cover most of their academic curricula and able to evaluate its impact on their research knowledge and skills development. We emailed a semi-structured questionnaire to the students in all 11 academic institutions where qualitative data collection was done and we received 297 responses. The specific aims of the survey were to explore knowledge regarding risk factors for NCDs among students, to report their perceived research skills, identify barriers to conducting research and also identify the proportion of students with an interest in pursuing a research career in NCDs and their risk factors.

\section{Ethical considerations}

The study was reviewed and approved by the NHRC prior to the data collection (Ref. number: 1467). Approval letters were taken from all the academic institutions that were selected for data collection. All participants provided verbal informed consent. For the qualitative study, the consent included permission for the audio recording. Confidentiality of the participants was maintained at each step of the study.

\section{Results}


We analyzed findings of the qualitative $(n=14$ FGDs, $n=25$ IDIs, and $n=6$ KIIs) and quantitative studies $(n=297)$ and desk review. We triangulated the results on existing gaps in the research training focusing on NCDs, capacity building, scientific environment, and administrative resources in academic health institutions.

Discrepancies in research methodology coverage in different academic programs

The curricula review revealed that the research methodology component was addressed differently across academic programs. It exists as a separate subject with a mandatory thesis in BPH, MPH, and MD community medicine curricula. The MBBS curriculum does not emphasize research methodology; research methods are taught as a topic within the community medicine/health subject in their curriculum.

The MD community medicine curriculum focuses on active self-learning with faculty assistance and a thesis as a research outcome at the end of the course. $\mathrm{BPH}$ and MPH students have regular theory classes with a compulsory thesis/research project at the end of program. MPH students during the FGDs shared that additional research classes for a specialization course in the second year are also provided: "Our friends specializing in health promotion study have separate health promotion course and we have health service management."

MD Community Medicine students shared that research methodology is taught through active self-learning and there are no formal classes: "There is no concrete syllabus focusing on formal class for research. We learn while conducting our thesis through preceptors assigned to us." In some institutes, however, MD students received combined classes with MPH students. In addition to formal theory classes, students also learnt about research through trainings and orientations organized by various institutions. MD community medicine students mentioned that they attended research methodology trainings conducted by NHRC: "We attended trainings, workshops of NHRC which help us in basic proposal development and data management." Moreover, MD students believed that formal regular classes for research are more effective than short orientations on proposal writing, which are given in mass by some universities in Nepal. Moreover, a majority of students stated that a research methodology module initiated early in the program and targeting thesis writing would be more productive than towards the end of the program.

Perceived gaps between the content of the curriculum and its implementation

Students expressed that more time should be allocated for research, especially for developing and practice of research skills. A BPH student commented: "The time allocated for research is inadequate, so we study in a very superficial manner. While some students might need less time to understand, others will need more time to properly understand research."The time gap between theory classes and their practical implementation in the academic program was also mentioned as a problem by some students: "Our curriculum is theory-based in 1st year and when we come to 2nd year it is totally practical based. So, if we had some practical in 1st year, it would be easier for us in 2nd year" (BPH student).

Many students shared that topics of the curriculum were not entirely covered in the classes. "Our curriculum is very detailed and covers a lot of aspects, but the teachers tell us that they are not required, and they don't cover many topics as mentioned in curriculum"(MPH student). The majority of the students expressed the need to incorporate qualitative research methodology in the formal class with equal importance to quantitative study methodologies. According to one of the MPH students, "qualitative research has not been touched at all even though it's mentioned in the curriculum." Another MPH student remarked, "We are mainly focused on quantitative analysis. We do not have proper knowledge of qualitative analysis, which is the reason we hesitate to include qualitative study in our thesis. We don't think we are that competent to conduct qualitative analysis because of that."

Superficial knowledge and practical skills lead to low confidence in research capability

Students felt that their knowledge on research is superficial, and therefore, they have low confidence: "We tend to learn research just for the sake of making a proposal to submit to the college to get marks. So, we only tend to get what research is only after we finish our own thesis" (MPH student). Students expressed their dissatisfaction with limited access to statistical software: "We all write entered in EpiData and analyzed in SPSS. But we all use pirated versions of SPSS which is unethical. But no one stops us from using this software. The University has not provided us software like SPSS, STATA for analysis. We all use a pirated version and write it with pride in our report even though we know it is unethical. There is free software available that can be just as useful for analysis, but we are not taught about them here" (MPH student).

Most of the participants reported that they felt confident to conduct descriptive research after the completion of their thesis. However, some students expressed the opinion that there is not enough practical exposure to research in their academic program: "It seems like we did thesis only for the sake of doing it... I still don't clearly know how to write a rational or formulate a research question" (BPH student). Data analysis in particular was a skill that most students felt lacking: "We are weak in the computer application and analysis part"(MPH student).

This was confirmed in the quantitative survey in which one-third (33.7\%) of students felt they lacked skills for analysis and interpretation of data (Fig. 3). However, findings of the survey showed that a majority of MBBS students felt that they had skills for literature search (92.2\%) and interpretation of scientific literature (85.9\%).

NCDs and their risk factors are not given enough emphasis in the curriculum

The curriculum review revealed some variations between universities and academic programs with regard to emphasis given to NCDs. Universities with a more recent MPH program have newer curricula in which NCDs are taught as a separate module. The universities that have been offering the academic programs for a longer period of time have not updated their curricula for many years and NCDs are not emphasized. Thus, during FGDs, some students expressed their dissatisfaction regarding coverage of NCDs in their curriculum. They believe that due to the changing pattern of diseases in Nepal, NCDs should be given equal priority to other health problems such as maternal and child health and communicable diseases.

Page $4 / 11$ 
$\mathrm{BPH}$ and MPH curricula focus on NCDs and their risk factors epidemiology, preventive measures, international and national programs, and policies to address NCDs. However, the curricula do not cover research methodology for NCDs in detail. BPH programs cover the epidemiology, the risk factors, national plans and policy on NCDs. MPH programs, in addition, also covers recent advances in the field of NCDs. However, students mentioned that specific objectives in the curriculum regarding NCDs were lacking: "They have just written the topic of NCDs. We don't know what we should study in it. We just have a topic and that's it"(MD Community Medicine student).

The MBBS programs address NCDs from both a clinical and preventive perspective with more emphasis on clinical aspects. The prevention of NCDs is superficially covered as a part of community medicine subject. Likewise, MD community medicine students stated, "We emphasize on active learning. Our learning about NCDs is mostly based on seminar presentations by the students themselves."

Scope for NCDs research in Nepal is rising

The students believed that research creates evidence for policy makers to develop policy and programs for the prevention and control of NCDs. They also expressed the need for more research in the field of NCDs for the establishment of disease registries and assessment of risk factors on the basis of the local context. Students shared that there is a broad range of unexplored topics within NCDs in Nepal to be approached through research: "NCDs are diseases that can be prevented if the risk factors are controlled so, there is a scope to move ahead" (MPH student). Students felt that there is a wide range of unexplored areas within NCDs in Nepal which is a good opportunity to conduct research: "It is a new topic, since there hasn't been much research in Nepal, so it is an opportunity for new research plus do the publication... such research will also be an opportunity for us to receive data" (MD student).

Findings from the quantitative survey complemented the qualitative data. More than half of the survey respondents (59\%) showed high interest in pursuing a research project after completing their course. Out of these, most of respondents ( $90 \%)$ showed interest in pursuing an NCD-specific research project. A majority of respondents (85\%) reported that they have an interest in pursuing a career that involves conducting NCD-related research (Fig. 4$)$.

Moreover, academic representatives from many institutes (IDIs and KIIs) opined that the interest of research has shifted from communicable diseases to NCDs. According to Institutional Review Board members, the proportion of NCD-related proposals submitted is about $20 \%$ of total proposals and its proportion is increasing over the time.

Most of the NCD studies are cross-sectional in design

The studies on NCDs are mostly done by the Department of Medicine, Department of Community Medicine, and Department of Public Health with a majority of them being prevalence studies: "Prevalence study is most common while proposals related to risk factors are not submitted much because people find it difficult to answer risk factor questions" (Institutional Review Board representative). This statement was also verified by our literature search in PubMed. There were 15 articles on the subject of cancer, 24 articles on the subject of diabetes, 37 articles on the subject of COPD, and 44 articles on the subject of cardiovascular diseases and hypertension. More than half (54\%) of the articles were published in international journals and the rest in national journals. A majority of the articles (117 of 120 articles) claimed absence of any financial support for research. Observational study design was most common (94\%), with cross-sectional studies in particular highly prevalent $(77 \%)$.

Enabling factors and barriers to conducting NCD research as perceived by the respondents

Among the enabling factors for conducting NCD research, students mentioned the availability of trained human resource and interest of international donor organizations to fund NCD research. In particular, students pointed out the availability of national governmental funding agencies who have begun to prioritize NCDs for research funding: "NHRC provides research grants for students and NCD is a prioritized topic"(BPH student).

On the other hand, government officials stated that research is given less priority by the government, which affects budget allocated for research activities: "The health workers at public sector should be directly involved in implementation research activities, and incorporate research components along with services. For that, it is very important to add up in their capacity building. Yet the Government of Nepal has not been giving much attention in capacity building of health workers for research" (Ministry of Health and Population official).

The IDIs revealed that academic promotion was a common motivating factor for faculty to conduct research while the students conducted research mostly for thesis completion. They also believed that provision of research grants for faculty will motivate them to do research. Respondents of the Klls pointed towards the importance of collaboration between government and academic institutes for research, which can motivate faculty to conduct research: "If government trust academia instead of inviting independent consultants and involves academia in the research projects we can also mobilize our students there" (Academic faculty). Furthermore, students shared that increasing awareness among people about research contributes toward their better cooperation during data collection: "People use to think that their data will be sold off for money - such perception is not there nowadays. They have understood to a certain extent that their information will be used to make plans and policy" (BPH student). Additionally, most of the respondents of the qualitative study shared the opinion that the availability of specialized hospitals like cancer hospitals, which generate a large amount of data on NCDs and easy access to these data, are important enabling factors for research in NCDs.

Regarding barriers for conducting NCD research, the students emphasized that curative aspects of NCDs are given more priority in Nepal than research on prevention and health promotion: "I see lots of opportunities in NCDs when I look at the data now. But, since our government is fully focused on the curative aspect, it is a great challenge for us to move forward in this aspect" (MPH student).

Inadequate training for advanced research tools were also reported as a major barrier in conducting NCD research: "While we might be able to conduct crosssectional or case-control study design, we still can't conduct cohort or randomized control trials, since we don't know the methodology for such research" (MD

Page 5/11 
community medicine student).

Similarly, respondents of the KIls believed that research capacity building in relation to NCDs in public health is important for Nepal. They shared that emphasis also should be given on multi-sectoral and inter-institutional collaboration to develop research capacity as well as for conducting advanced research: "We should make a pool of researchers including experts of various fields of research like an expert in the meta-analysis, an expert in systemic review, an expert in NCDs" (Academic faculty). Thus, research trainings and workshops with an emphasis on enhancing practical skills were suggested by KIl: "A basic level training and continuous follow up with a mixed group including faculties and human resources of other institutions shall benefit. If we don't give them hands-on training and real opportunity to work in the field they are not going to learn" (Academic faculty).

IDIs also highlighted underestimation of research values in Nepal as an important barrier for research: "There is absence of research culture in the academic sector especially among the senior faculty. People have the concept that "I am already a professor now why should I do research?" (Academic faculty), and, "Faculty have been showing keen interest in research nowadays, however, the question is whether they are doing research to fulfill the academic criteria for promotion or they are really doing for the matter of passion, that is something that needs to be explored further" (Academic faculty).

The KIls also pointed at administrative barriers for conducting research in Nepal: "Lack of strong administration, as well as improper coordination with the administration, has been hampering the research activities in institution" (Academic faculty). Students shared that unavailability of primary data or proper registries makes it harder to conduct NCDs research: "We have been reporting communicable diseases to Health Management Information System (HMIS) but I don't think there is a reporting form in HMIS for NCDs. So, I think that acts as a barrier. No primary data is available. We have to start from the very basic level" (MD community medicine student).

Lack of funding is another barrier that was reported as the reason for the limited number of interventional studies in the country: "I am a student and I want to do research in NCDs, and I have research that involves clinical testing. But how can I do it when I don't have a resource to obtain those tests?" (BPH student). These findings were supported by the quantitative survey (Table 1).

Table 1

Perceived Barriers in conduction of Research by MBBS students $(\mathrm{n}=$

\begin{tabular}{|c|c|}
\hline 297) & \\
\hline Barriers & Percentage (\%) \\
\hline Lack of funds & 92.6 \\
\hline Lack of awareness & 91.2 \\
\hline Lack of training opportunities & 91.3 \\
\hline Lack of self interest & 83.8 \\
\hline Supervising faculty & 82.7 \\
\hline Lack of encouragement/academic environment & 79.0 \\
\hline Lack of time & 72.5 \\
\hline
\end{tabular}

\section{Discussion}

Strong research capacity and environment are critical prerequisites for NCDs prevention and control. For this reason, the World Health Organization Global NCD Action Plan 2013-2020 aims to promote and support national capacity for high-quality research and development for the prevention and control of NCDs [17]. However, the latest global assessment of national capacity for the prevention and control of NCDs (2019) revealed that only 33\% of countries had an operational NCDs-related research policy or plan that included community-based research and an evaluation of the impact of interventions and policies [18]. However, these documents do not overtly discuss the need of skilled human resources in research, something which is reflected also in the national NCD action plan of Nepal [11]. Capable human resource is a clear prerequisite for meaningful implementation of WHO's Guide to implement research in the prevention and control of NCDs [19]. Particularly in the context of LMICs like Nepal, research capacity strengthening needs to be done proactively and in a planned manner $[12,20]$.

Our study has revealed the potential for increasing NCD research capacity in Nepal. There is insufficient emphasis on NCD research in graduate and postgraduate level of medical and public health teaching. In the past 10 years, most NCD-related research was either national level surveys or small cross-sectional studies. Methodologically advanced studies including longitudinal research with or without interventions are rare. Hence, improvement in NCD research capacity including research skills, research management, and fund generation is the current need. Studies from other countries have revealed similar findings [21].

Research capacity should be enhanced from the undergraduate level

There is a dire shortage of investigators who are well trained to conduct research in NCDs in Nepal. This stems from the fact that research is not adequately and uniformly reflected in the undergraduate and postgraduate health-related disciplines. Due to the self-learning nature of post-graduate residency programs, the residents find it difficult to grasp the basic concepts of research methods before conducting their thesis. Although some universities and institutes organize a short-term orientation or training on research methods for postgraduates, these are often not adequate. The concept of research was not included 
mostly as a theory paper in a majority of MBBS curricula of Nepal. To address this gap, some institutions have introduced research methods in the MBBS curricula providing the students opportunity to conduct small-scale doable research [22, 23].

Post-Masters capacity building efforts must be strengthened

Research culture in general is still very naive in Nepal. The higher education system of the country is yet to adapt to the international research concepts such as post-doctoral positions. In any case, there are limited opportunities to do doctoral studies in Nepal, and more so, in NCDs. One of the reasons for this is the limited number of faculty specialized in NCDs. However, some of the global programs such as The Bernard Lown Scholars in Cardiovascular Health Program at the Harvard T.H. Chan School of Public Health, have provided opportunities for Nepalese researchers to sharpen their capacity in cardiovascular health research [24]. Furthermore, emphasis must also be given to foster research culture and capacity at the institutional level, and not only at the individual level, so that administrative barriers are minimized, and research endeavors are enabled rather than hindered [25].

Furthermore, due to the transdisciplinary nature of NCDs, we need to train researchers in different disciplines or bring together leaders from different disciplines to work together. We need to foster partnerships with NCD leaders with support from major global funding agencies. An example of one such initiative in Nepal is the translational research capacity building in cardiovascular disease funded by The National Heart, Lung, and Blood Institute (NHLBI) [26, 27]. There are examples of collaboration of institutions from LMICs partnered with research institutions from high-income countries [28]. More of such initiatives will help link the subject matter experts, who are typically widely cited scholars with multiple funded projects, with local level expertise who are more familiar with contextual matters and ground realities.

NCD research funding must be increased

Lack of funding for health research has been a major barrier to researchers from Nepal to conduct studies on NCDs. There is global disproportionate allocation of research funding which favors communicable diseases more compared to NCDs [29, 30]. NCDs account for $60 \%$ of global disability adjusted life years and $70 \%$ of global deaths but receive less than two percent of health research funding [29]. Communicable diseases have clearer cause-effect relationship which make interventions generate desirable outcomes on time. NCDs on the other hand run a more chronic course than infectious diseases with multifactorial nature of causation. The most effective interventions for NCDs are population-based with multi-sectoral approach with includes medical, academic, and administrative domains [29]. This demands greater resources to conduct high-quality research and generate robust evidence that can inform policy.

The major source of national funding for Nepalese health researchers comes from the health research funding allocated from total health budget, which is channeled through different universities and councils. NHRC and University Grants Commission provide research funding in the form of grants which are given across levels, from undergraduate to post-graduate and faculty. Provision of grants at the undergraduate level is an appreciable step to instill research interest in students which will help build a strong research portfolio that is needed to pursue a future career in research. However, the amount of funding allocated for health research is less in proportion to the total health budget. This translates to a very meagre amount at the level of the researcher, which can be utilized to conduct only small sample surveys. Large-scale studies with longitudinal design and randomized controlled trials, which are typical of NCD research, are only possible with significant funding from high-income countries, and not all Nepalese researchers have the capacity to apply for such grants [31]. Even though NHRC has been advocating for increment in health research budget to at least $2 \%$ of the total national health budget [32], there needs to be significant increment to cadre the capacity building of Nepalese researchers in NCDs.

\section{Strengths And Limitations Of The Study}

This study explored the research capacity among the public health, medical and community medicine graduates, particularly in NCDs, for the first time in Nepal and one among few globally. We looked at the perspectives of both the students and the teachers, as well as the government stakeholders.

Triangulating the findings from qualitative, quantitative, and desk reviews is another strength of the study. Further, our research has reached out to most of the geographic locations of Nepal where medical and public health institutes are located. Also, in terms of respondents, it has a good mix of respondents from governmental and private sector institutes. However, the study has some limitations. Awareness about the background of the researchers could have led to some amount of information/researcher bias, and hence our qualitative and quantitative data results could be partially affected by this. Due to the current pandemic, we could not do face-to face quantitative data collection, and therefore, we reached out to the students online through the institutional faculties. Though we did not calculate a sample size, we received responses from a lesser number of respondents than expected, and our sample is likely to suffer from sampling bias as well. Additionally, we use only PUBMED data base for articles search that, therefore we could miss some publications.

\section{Conclusion}

In order to enhance its efforts towards prevention and control of the rising burden of NCDs, Nepal must generate local evidence based on epidemiological studies that measure disease burden, evaluate programs, explore feasibility of interventions, and analyze policies. For this, Nepal must strengthen the whole spectrum of research capacity: epidemiological skills, research management, and fund generation. This should begin at the level of undergraduate and postgraduate public health training. University curricula should match up with the NCD burden of the country and must emphasize on applied practical research projects. Generation of a critical mass of NCD researchers must be go together with improved NCD funding from the government, non-governmental organizations, and external funding organizations.

\section{Abbreviations}

BPH: Bachelor in Public Health 
COPD: Chronic obstructive pulmonary diseases

EDCD: Epidemiology and Disease Control Division

FGD: Focus Group Discussions

HMIS: Health Management Information System

IDI: In-depth interviews

IOM: Institute of Medicine

KII: Key Informant Interviews

KMCPL: Kathmandu Medical College Public Limited

KUSMS: Kathmandu University School of Medical Sciences

LMICs: Low and middle-income countries

MBBS: Bachelor of Medicine and Bachelor of Surgery

MPH: Masters in Public Health

NCDs: Non-communicable diseases

NHTC: National Health Training Center

NHRC: Nepal Health Research Council

NHLBI: The National Heart, Lung, and Blood Institute

PAHS: Patan Academy of Health Sciences

\section{Declarations}

\section{Ethics approval and consent to participate}

The study was approved by Nepal Medical Research prior to the data collection (Ref. number: 1467). Approval letters were taken from all the academic institutions that were selected for data collection.

Informed consents were obtained from the respondents prior to the interviews and the study was conducted in accordance to the tenets of the Declaration of Helsinki. Anonymity and confidentiality of respondents in this study were assured, with no personal identifiers collected.

\section{Availability of data and materials}

The datasets used and/or analyzed during the current study are available from the corresponding author on reasonable request.

\section{Competing interests}

The authors declare that they have no competing interests.

\section{Consent for publication}

Not applicable.

\section{Funding}

This research is supported by the Fogarty International Center of the National Institutes of Health

(Grant \#: 1D71TW011468-01). The funding body had no role in the design of the study and collection, analysis, and interpretation of data and in writing the manuscript.

\section{Authors' contributions}

NO, AV, PMP, RS conceptualized the study. They also supervised data collection. NO and RS analyzed and interpreted the results. LJ, GD, AS and BMK provided feedback during data collection and analysis. NO, AV, PMP and RS wrote the manuscript. LJ, AS, GD and BK review the manuscript. All authors read and approved this version for publication.

\section{Corresponding author}




\section{Acknowledgements}

The authors are grateful to Prativa Bhandari and Priyanka Timsina for their assistance with data collection and analysis. We acknowledge academic institutions which were involved in the study for their cooperation. We appreciate the contribution of all involved in the study.

\section{References}

1. Allen L, Cobiac L, Townsend N. Quantifying the global distribution of premature mortality from non-communicable diseases. Journal of Public Health. 2017;39(4):698-703.

2. Sturke R, Vorkoper S, Duncan K, Levintova M, Parascondola M. Addressing NCDs through research and capacity building in LMICs: lessons learned from tobacco control. Global health action. 2016;9:32407. doi:10.3402/gha.v9.32407

3. Mendis S. Global status report on noncommunicable diseases 2014: World Health Organization; 2014. https://apps.who.int/iris/bitstream/handle/10665/148114/9789241564854_eng.pdf. Accessed 15 September 2019

4. Pandey AR, Chalise B, Shrestha N, Ojha B, Maskey J, Sharma D, et al. Mortality and risk factors of disease in Nepal: Trend and projections from 1990 to 2040. PLoS ONE. 2020. 15(12): e0243055. https://doi.org/10.1371/journal.pone.0243055

5. Murray CJ, Aravkin AY, Zheng P, Abbafati C, Abbas KM, Abbasi-Kangevari M, et al. Global burden of 87 risk factors in 204 countries and territories, $1990-$ 2019: a systematic analysis for the Global Burden of Disease Study 2019. The Lancet. 2020;396(10258):1223-49.

6. Dhimal M BB, Bhattarai S, Dixit LP, Hyder MKA, Agrawal N, Rani M, Jha AK. Report of Non Communicable Disease Risk Factors: STEPS Survey Nepal 2019. Kathmandu: Nepal Health Research Council 2020. https://www.who.int/docs/default-source/nepal-documents/ncds/ncd-steps-survey-2019compressed.pdf?sfvrsn=807bc4c6_2. Accessed 20 Aug 2019.

7. Karki KB, Dhakal P, Shrestha SL, Joshi HD, Aryal KK, Poudyal A, et al. Situation analysis of ambient air pollution and respiratory health effects in Kathmandu valley. Nepal Health Research Council; 2016.

http://library.nhrc.gov.np:8080/nhrc/bitstream/handle/123456789/788/Situation\%20analysis\%20of\%20ambient\%20air\%20pollution\%20and\%20respiratc sequence=1. Accessed 5 Oct 2020.

8. Dhimal M. Karki K, Aryal KK, Dhakal P, Joshi HD, Pande AR, et al. Indoor Air Pollution and its effects on Human Health in llam District of Eastern Nepal. Kathmandu Government of Nepal, Nepal Health Research Council (NHRC). 2016. http://nhrc.gov.np/wp-content/uploads/2017/06/Indoor-airpollution.pdf. Accessed 5 Oct 2020.

9. Meghnath D, Khem Bahadur K, Sanjib Kumar S, Krishna Kumar A, Namuna S, Anil P, et al. Prevalence of Selected Chronic Non-Communicable Diseases in Nepal. Journal of Nepal Health Research Council. 2019;17(3).

10. Nepal Goverment. Multisectoral Action Plan for the Prevention and Control of Non-communicable diseases (2014-2020). Government of Nepal and World Health Organization, editor Kathmandu, Nepa; 2010. https://extranet.who.int/ncdccs/Data/NPL_B3_ncd_multisectoral_action_plan.pdf. Accessed 11 Sept 2019.

11. Vaidya A. Capacity building: A missing piece in Nepal's plan for prevention and control of non-communicable diseases. Journal of Kathmandu Medical College. 2018;7(4):131-3.

12. Sturke R, Vorkoper S, Duncan K, Levintova M, Parascondola M. Addressing NCDs through research and capacity building in LMICs: lessons learned from tobacco control. Global Health Action. 2016;9(1):32407.

13. UNDP. Technical advisory paper. Oxford University Press, Inc 1999.

14. McKee M, Stuckler D, Basu S. Where There Is No Health Research: What Can Be Done to Fill the Global Gaps in Health Research? PLOS Medicine. 2012;9(4):e1001209.

15. The Lancet Global Health. Lessons in humility. Lancet Glob Health. 2021 Jul;9(7):e880. doi: 10.1016/S2214-109X(21)00268-0. PMID: 34143981.

16. Global Forum for Health Research. The 10/90 Report on Health Research 2003-2004. Geneva, Switzerland 2004. https://www.files.ethz.ch/isn/17141/1090.04.pdf. Accessed 6 Oct 2019.

17. World Health Organization. Global action plan for the prevention and control of noncommunicable diseases 2013-2020: WHO; 2013. https://www.who.int/publications/i/item/9789241506236. Accessed 5 Nov 2019.

18. World Health Organization. Assessing national capacity for the prevention and control of noncommunicable diseases: report of the 2019 global survey. WHO; 2019. https://www.who.int/publications/i/item/ncd-ccs-2019. Accessed 11 Nov 2019.

19. World Health Organization. A guide to implementation research in the prevention and control of noncommunicable diseases. WHO; 2016. https://apps.who.int/iris/bitstream/handle/10665/252626/9789241511803-eng.pdf. Accessed 8 Oct 2019.

20. Malekzadeh A, Michels K, Wolfman C, Anand N, Sturke R. Strengthening research capacity in LMICs to address the global NCD burden. Global Health Action. 2020;13(1):1846904.

21. Kilic B, Phillimore P, Islek D, Oztoprak D, Korkmaz E, Abu-Rmeileh N, et al. Research capacity and training needs for non-communicable diseases in the public health arena in Turkey. BMC Health Serv Res. 2014;14:373.

22. SCIENCES BPKIOH. The MBBS curriculum of B. P. Koirala Institute of Health Sciences, Dharan. 2014.

23. Medicine PSo. Undergraduate Medical (MBBS) Curriculum Patan Academy of Health Science; Revised 2020. 
24. Health HTHCSoP. The Bernard Lown Scholars in Cardiovascular Health Program: Harvard T.H. Chan School of Public Health [Available from: https://www.hsph.harvard.edu/lownscholars/]

25. Haregu TN, Byrnes A, Singh K, Sathish T, Pasricha N, Wickramasinghe K, et al. A scoping review of non-communicable disease research capacity strengthening initiatives in low and middle-income countries. Global Health Research and Policy. 2019;4(1):31.

26. Medicine NNLo. National Information Center on Health Services Research and Health Care Technology (NICHSR). Information about ongoing health services research and public health projects 2017 [Available from: https://hsrproject.nlm.nih.gov/view_hsrproj_record/20182495]

27. Archana S, Karmacharya B, Maharjan R, Vaidya A, Dhimal M, Oli N, et al. Stakeholder Engagement in Planning the Design of a National Needs Assessment for Cardiovascular Disease Prevention and Management in Nepal. Global Heart. 2019;14:181-9.

28. Bloomfield GS, Xavier D, Belis D, Alam D, Davis P, Dorairaj P, et al. Training and Capacity Building in LMIC for Research in Heart and Lung Diseases: The NHLBI-UnitedHealth Global Health Centers of Excellence Program. Glob Heart. 2016;11(1):17-25.

29. Allen L. Non-communicable disease funding. Lancet Diabetes Endocrinol. 2017;5(2):92.

30. Shrestha S. Challenges and opportunities of public Health Research in Nepal. Kathmandu University Medical Journal. 2014;12(1):1-3.

31. Sharma JR, Khatri R, Harper I. Understanding health research ethics in Nepal. Developing world bioethics. 2016;16(3):140-7.

32. Nepal Health Research Council. Health Research System In Nepal. NHRC; 2006. http://nhrc.gov.np/wp-content/uploads/2017/02/Health-ResearchSystem-Nepal-2006.pdf. Accessed 25 Sept 2019.

\section{Figures}

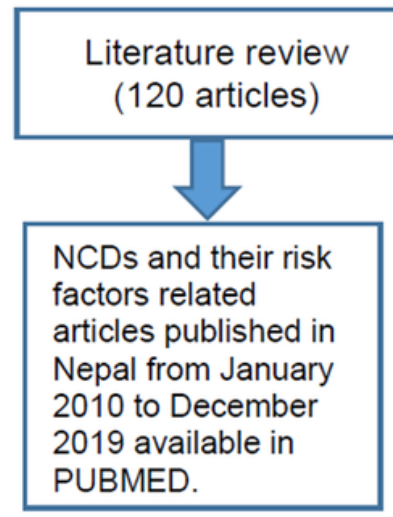

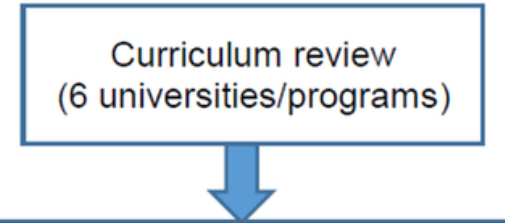

- Tribhuvan University (IOM-TU)

- Kathmandu University School of Medical Science (KUSMS)

- Patan Academy of Health Sciences (PAHS)

- Pokhara University

- Purbanchal University

- B.P. Koirala Institute of Health sciences (BPKIHS)

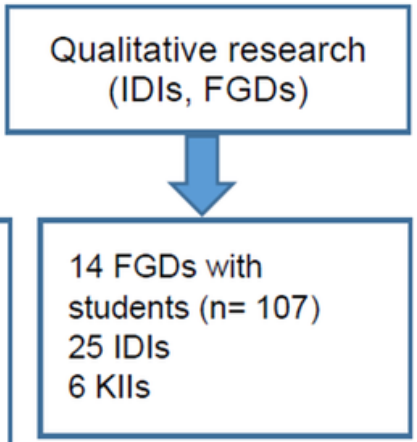

Quantitative online survey among students $(n=297)$

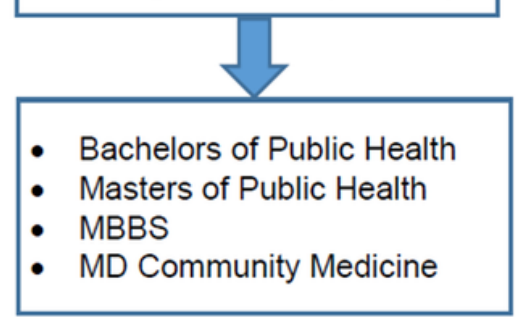

- Bachelors of Public Health

- Masters of Public Health

- MBBS

- MD Community Medicine

\section{Figure 1}

Summary of needs assessment methodology. FGD: Focus Group Discussions, IDI: In-depth interviews; KII: Key Informant Interviews; MBBS, Bachelor of Medicine and Bachelor of Surgery; NCDs, non-communicable diseases.

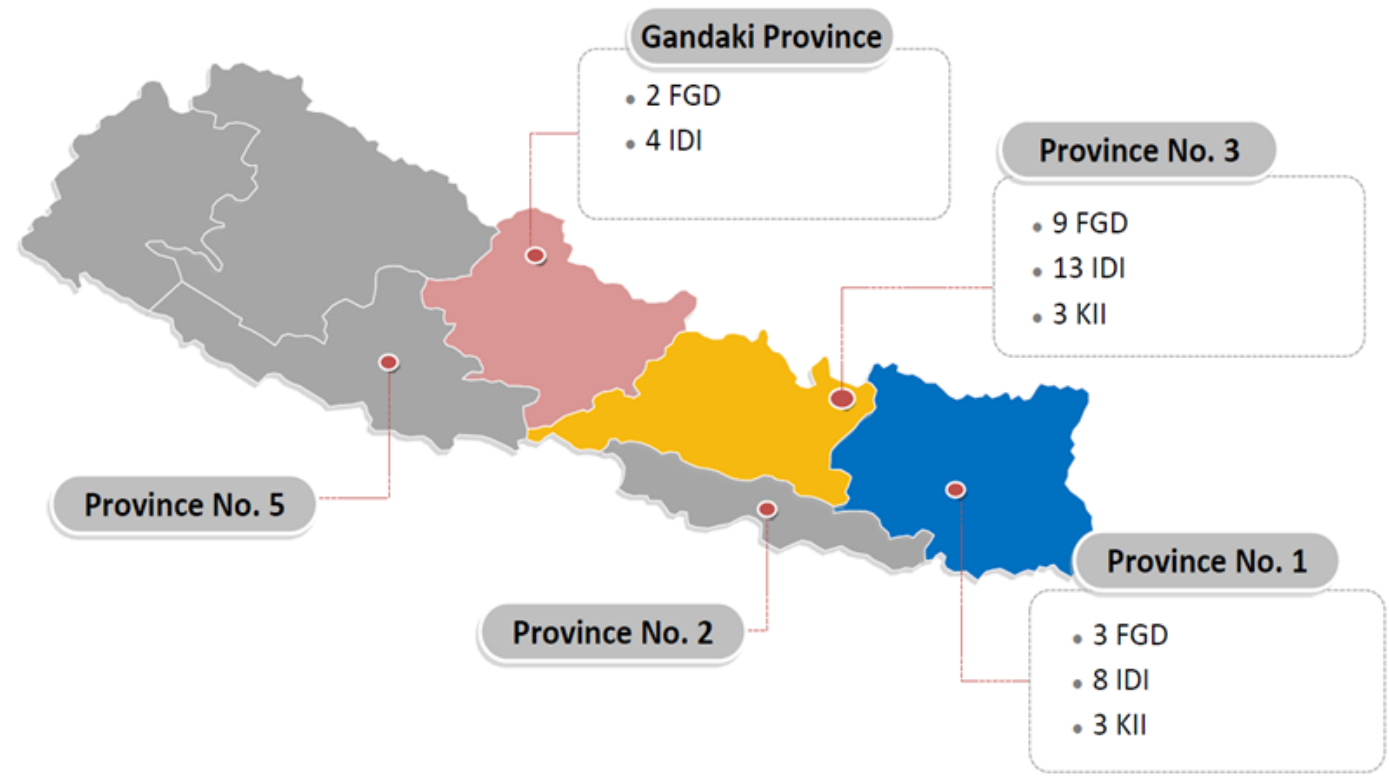


Figure 2

Province map of Nepal depicted sampling for qualitative data collection. (Source of the map: https://favpng.com/png_view/fundamental-rights-nepal-nepalvector-graphics-royalty-free-map-illustration-png/3UJQEh9T. Map was modified by authors using Microsoft PowerPoint 2016)

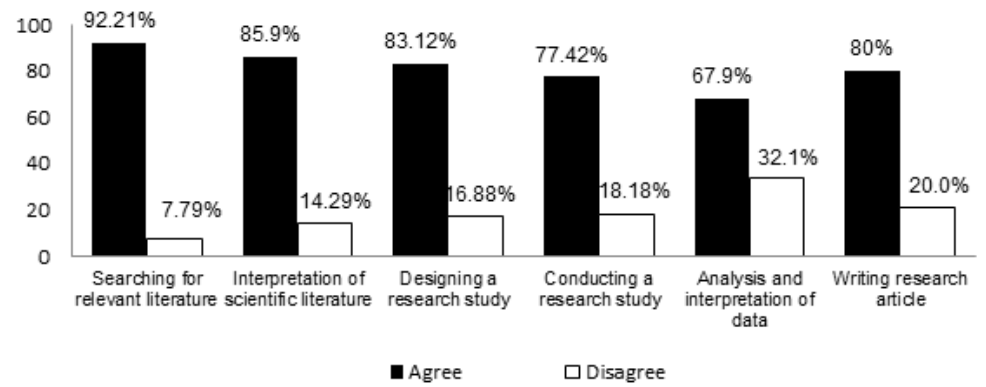

Figure 3

Nepal MBBS students' perceived research skills in general $(n=297)$.

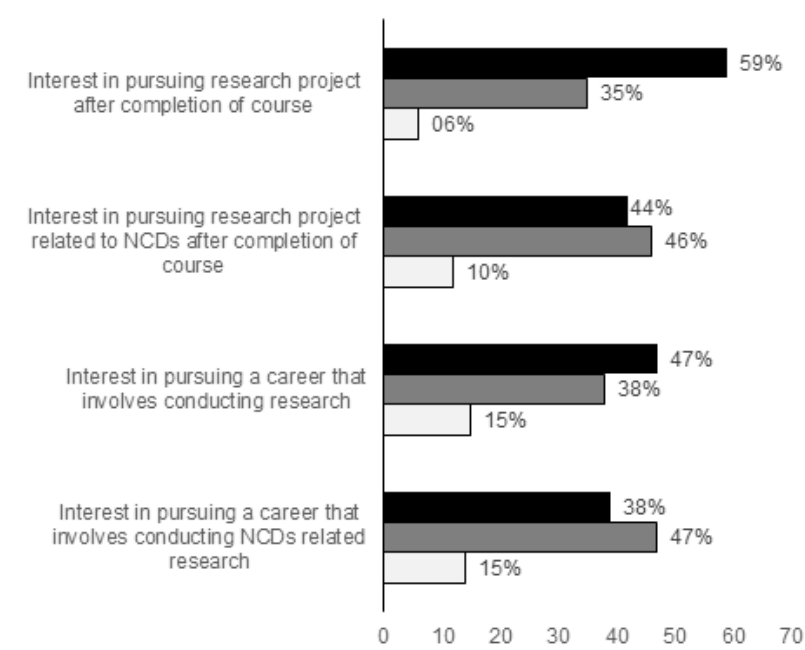

- Highly interested alnterested aNot interested

\section{Figure 4}

Proportion of MBBS respondents with interests in career in NCDs $(n=297)$ 